\title{
Mechanical Ventilation in the Prehospital and Emergency Department Environment
}

\author{
Robert J Stephens, Jeffrey E Siegler, and Brian M Fuller \\ Introduction \\ The Concept of Ventilator-Induced Lung Injury as a Time-Sensitive \\ Emergency \\ Prehospital Mechanical Ventilation \\ The Landscape of Prehospital Mechanical Ventilation \\ Complications Associated With Prehospital Mechanical Ventilation \\ Clinical Impact of Prehospital Ventilatory Care \\ Emergency Department Mechanical Ventilation \\ Landscape of Mechanical Ventilation Provided in the Emergency Department \\ Clinical Impact of Mechanical Ventilation in the Emergency Department \\ Summary and Recommendations
}

\begin{abstract}
Patients who require mechanical ventilation in the prehospital and emergency department environments experience high mortality and are at high risk of ventilator-associated ventilator-induced lung injury and ARDS. In addition, little attention has been given in the literature, trainee education, or clinical emphasis to ventilator management in these patients. ARDS and ventilator-induced lung injury are time-sensitive disease processes that develop early in mechanical ventilation and could potentially be prevented with early lung-protective ventilation. Prehospital and emergency department ventilation, in general, is characterized by potentially injurious tidal volume, high $\mathrm{F}_{\mathrm{IO}_{2}}$, and low PEEP. Recent literature highlights improved subjects outcomes in the setting of early lung-protective ventilation in both subjects with and those without ARDS. This review of the literature led us to recommend that lung-protective ventilation with avoidance of hyperoxia be the default goal ventilator strategy for all patients with prehospital and emergency department mechanical ventilation. This can be achieved by delivering low tidal volumes with stepwise, concurrent titration of $\mathbf{F}_{\mathrm{IO}_{2}}$ and PEEP to facilitate adequate oxygenation. Key words: mechanical ventilation; prehospital; emergency department; ventilator-associated lung injury; lung-protective ventilation. [Respir Care 2019;64(5):595-603. (c) 2019 Daedalus Enterprises]
\end{abstract}

\section{Introduction}

Patients who require mechanical ventilation in the prehospital and emergency department environment experi-

Mr Stephens is affiliated with Washington University School of Medicine in St. Louis, St. Louis, Missouri. Dr Siegler is affiliated with the Section of Emergency Medical Services, Division of Emergency Medicine, Washington University School of Medicine in St. Louis, St. Louis, Missouri. Dr Fuller is affiliated with the Division of Critical Care, ence high mortality and morbidity. ${ }^{1}$ Mechanical ventilation can lead to iatrogenic injury via ventilator-induced lung injury as well as hyperoxia. Phenotypically, this usually presents as worsening pulmonary mechanics, pneumonia, and/or ARDS, with the peak incidence occurring

\footnotetext{
Division of Emergency Medicine, Department of Anesthesiology, Washington University School of Medicine in St. Louis, St. Louis, Missouri.
}

The authors have disclosed no conflicts of interest. 
early in the course of mechanical ventilation (ie, day 1 or day 2).2,3 This suggests that appropriate management of mechanical ventilation immediately after endotracheal intubation is crucial, and emerging evidence has demonstrated a vital role for appropriate ventilator management in the prehospital and emergency department treatment of patients who are critically ill. Compared with the ICU or intraoperative environment, mechanical ventilation in the prehospital and emergency department setting has historically received very little attention in terms of research, trainee education, and clinical emphasis. ${ }^{4-6}$ As such, potentially injurious practice patterns are common. ${ }^{1,7,8}$

In this article, we discuss the landscape of mechanical ventilation and advances in scientific understanding in the care of patients with acute respiratory failure in the prehospital and emergency department settings. We provide recommendations for the provision of mechanical ventilation to patients in both of these environments. Although we recognize the importance of airway management and noninvasive positive-pressure ventilation, these topics are outside the scope of this review. In addition, many factors (ie, sedation, fluid administration, transfusions) play a role in the ultimate outcome of patients on mechanical ventilation in the emergency department; this review focused on the delivery of invasive mechanical ventilation. ${ }^{9,10}$

\section{The Concept of Ventilator-Induced Lung Injury as a Time-Sensitive Emergency}

Excessive stretch, regional lung overdistention, and repetitive airway opening all play roles in ventilator-induced lung injury and ARDS. ${ }^{11}$ Biologic mediators and hyperoxia can contribute to progressive pulmonary dysfunction, multiple organ failure, and death. ${ }^{12-14}$ In volutrauma, overdistention of alveoli results in damage to the intercellular junctions and the cellular membranes due to increased strain on pneumocytes. ${ }^{15}$ Similarly, barotrauma occurs when pneumocytes are damaged due to an increase in transalveolar pressure or stress. Cyclic recruitment-derecruitment as alveoli collapse between respirations results in atelectrauma, which increases stress at any given pressure due to reduced compliance. ${ }^{16,17}$ These forces are especially important in ARDS, when the amount of lung tissue available for gas exchange is reduced, often referred to as a "baby lung."17-19 Hyperoxia and the resultant reactive oxygen species formation are thought to cause injury both in the lung parenchyma and in sites distal to the

Correspondence: Robert J Stephens, Division of Emergency Medicine, Washington University School of Medicine in St. Louis, 660 S Euclid Avenue, St. Louis, MO, 63110. email: stephensr@wustl.edu.

DOI: $10.4187 /$ respcare. 06888 pulmonary system. ${ }^{12,13}$ Time- and dose-dependent increases in inflammatory markers have been observed in experimental animals that received mechanical ventilation. ${ }^{20-22}$

Before knowledge of the existence of ventilator-induced lung injury, normalization of oxygenation and ventilation was given priority. As such, mechanical ventilation strategies involved the delivery of high tidal volume $\left(\mathrm{V}_{\mathrm{T}}\right)(12-$ $15 \mathrm{~mL} / \mathrm{kg}$ predicted body weight [PBW]) and low levels of PEEP. ${ }^{23}$ Subsequently, seminal work in the field provided strong evidence that the mechanical ventilator can cause harm, as animal and ex vivo models clearly demonstrated the mitigation of lung injury by the application of lungprotective concepts (ie, lower $\mathrm{V}_{\mathrm{T}}$, more-appropriate PEEP). ${ }^{24-26}$ Perhaps most important to this review, on prehospital and emergency mechanical ventilation, these effects were observed over the course of only a few hours. ${ }^{24-26}$

Clinical studies that involved subjects without ARDS support this premise. ${ }^{4,27,28}$ Data that compared various strategies of lung-protective ventilation versus conventional ventilation during surgery showed that early application of lung protection for comparatively short durations can mitigate pulmonary and systemic inflammation and is associated with a reduction in pulmonary and extrapulmonary complications. ${ }^{29-31}$ Similarly, higher driving and plateau pressures among patients in the emergency department were associated with increased progression to ARDS. There was a dose-dependent, stepwise relationship with an increasing incidence of ARDS with increasing driving pressure, plateau pressure, compliance, and mechanical power. ${ }^{32}$

In subjects without ARDS and in the ICU, observational studies, ${ }^{2,33,34}$ a small randomized trial, ${ }^{27}$ and 2 systematic reviews ${ }^{4,28}$ showed an association between higher $\mathrm{V}_{\mathrm{T}}$ and increased incidence of ARDS, with a typical peak incidence around ICU day 2. This suggests that initial ventilator dosing influences downstream complications. In addition, in patients with ARDS, delayed delivery of lung-protective ventilation is associated with increased mortality. ${ }^{35}$

Multiple studies have shown that initial ventilator settings, both in the emergency department and the prehospital setting, influence ventilator settings that subjects received in the ICU. These settings remained unchanged in up to $75 \%$ of subjects through the first 24 h. $1,2,33,36-38$ Similar therapeutic momentum has been documented in other areas of critical care, such as sedation and antibiotic dosing, and may result in prolonged iatrogenic risk. 9,39 Therefore, the most immediate period of care is a potential therapeutic target to increase adherence to best practice. Because mortality in patients in the emergency department and on mechanical ventilation can exceed $30 \%^{1}$ and can be as high as $50 \%$ if ARDS develops, ${ }^{37}$ early use of these practices may have the potential to have a large impact on 
patient outcome. In sum, ARDS and ventilator-induced lung injury occur early in patients on mechanical ventilation and are time-sensitive processes that benefit from early recognition and treatment.

\section{Prehospital Mechanical Ventilation}

\section{The Landscape of Prehospital Ventilation}

Prehospital mechanical ventilation is delivered during $\sim 4 \%$ of emergency medical service activations annually in the United States..$^{40}$ Much of the data about prehospital care of patients who are critically ill comes from the realm of interfacility transport; however, even these data are limited to a few primarily observational studies. The majority of patients $(73-83 \%)$ receive volume control continuous mandatory ventilation during transport, with a minority receiving pressure control continuous mandatory ventilation or volume control intermittent mandatory ventilation. In a cohort study of subjects with hypoxemic respiratory failure, the mean $\pm \mathrm{SD} \mathrm{F}_{\mathrm{IO}_{2}}$ was high during transport $(0.95 \pm 0.12)$, and mean \pm SD PEEP was relatively low $\left(9.6 \pm 4.7 \mathrm{~cm} \mathrm{H}_{2} \mathrm{O}\right) .{ }^{41}$ The investigators note, however, that $\mathrm{F}_{\mathrm{IO}_{2}}$ is often increased preemptively in the prehospital setting to levels higher than would be in the ICU to prevent critical desaturation. ${ }^{41}$ The $\mathrm{V}_{\mathrm{T}}$ values are often high, with one cohort study that showed that low $\mathrm{V}_{\mathrm{T}}$ ventilation occurred in only $14 \%$ of subjects on prehospital ventilation. ${ }^{42}$

For the majority of patients who require prehospital ventilation, a transport ventilator is not available and bagvalve-mask is frequently used to provide ventilation, even among patients transported on aeromedical units. $.^{42} \mathrm{Al}-$ though, to our knowledge, there are no studies that compared patient-centered outcomes and the use of transport ventilators versus bag-valve-masks, one small randomized controlled trial (28 subjects) found that paramedics randomized to use transport ventilators believed that they were better able to perform patient care tasks than paramedics randomized to the use of a bag-valve-mask. ${ }^{43}$ In addition, the standard adult bag-valve-mask delivers highvolume, low-PEEP ventilation contrary to current recommendations for lung-protective ventilation. ${ }^{44}$ Manual ventilation with bag-valve-masks in simulated resuscitation scenarios has been shown to often deliver with high peak pressures, in certain scenarios that exceeded $100 \mathrm{~cm} \mathrm{H}_{2} \mathrm{O}$, even among experienced respiratory therapists..$^{45}$ Previous reviews recommend the use of adjustable, disposable PEEP valves when providing ventilation via bag-valve-masks for preoxygenation before intubation. ${ }^{46}$ The impact of PEEP valves on patient-centered outcomes in bag-valve-mask ventilation has not been studied, and it is unclear how often they are used in practice.
Emergency medical services providers are trained to ventilate in a way that achieves observable chest rise, yet bag-valve-masks do not provide feedback on the delivered $\mathrm{V}_{\mathrm{T}}$. Pneumotachograph devices are not routinely used or carried by emergency medical services providers. One simulation study demonstrated that the use of a standard pediatric bag-valve-mask resulted in a significantly greater proportion of $\mathrm{V}_{\mathrm{T}}$ in the $6-8 \mathrm{~mL} / \mathrm{kg}$ PBW range than the use of adult bag-valve-masks (17.7\% versus $5.1 \%) .{ }^{44} \mathrm{Me}-$ dian (interquartile range) $V_{T}$ delivered via endotracheal tube were also significantly greater when an adult bagvalve-mask (981.5 [901-1085] mL) was used compared with a pediatric bag-valve-mask (663 [615-696] mL). ${ }^{44} \mathrm{~A}$ separate simulation study demonstrated that gripping the bag-valve-mask with fewer fingers, in conjunction with pediatric bag size resulted in an even greater proportion of volumes being in a lung-protective range when compared with an adult bag-valve-mask alone ( $46.4 \%$ versus $0.4 \%) .{ }^{47}$ Analysis of these data indicated that injurious ventilation could occur in patients who receive ventilation via adult bag-valve-masks, although no patient-centered outcomes exist.

\section{Complications Associated With Prehospital Mechanical Ventilation}

Critical events (ie, major resuscitative procedure, hemodynamic deterioration, or inadvertent extubation) occur in as many as 1 in 20 aeromedical transports of patients who are critically ill, and the need for mechanical ventilation is independently associated with a 2- to 3 -fold increase in risk of critical events during transport. ${ }^{48,49}$ Hypoxemic episodes during transport have been reported with relatively high frequency across studies that measured this end point $(1.3-28 \%){ }^{48,50}$ Despite these risks, transfers of patients to facilities with higher levels of care are generally considered safe and deaths during transport are relatively rare, having occurred in $0.0-0.1 \%$ of transports described in the literature. ${ }^{41,48,51}$

Hypocapnia secondary to hyperventilation also occurs frequently during prehospital ventilation. This has been most commonly documented among patients with traumatic brain injury and occurred in up to $79 \%$ of patients. ${ }^{52,53}$ Prehospital hyperventilation and the resulting hypocapnia are associated with poor outcomes, including worsened mortality in multiple analyses. ${ }^{54-56}$ The major mechanism of this injury is believed to be decreased cerebral blood flow and vasoconstriction that causes ischemia in cerebral tissue. ${ }^{54-57}$ Use of prehospital quantitative end-tidal capnometry to avoid unintentional hypocapnia has been associated with a decreased incidence of hyperventilation. ${ }^{58}$ 


\section{Clinical Impact of Prehospital Ventilatory Care}

Changing transport practices have impacted the clinical course of prehospital patients. In particular, dedicated critical-care transportation teams can provide a similar level of care as an ICU. Patients treated by these teams experience fewer critical events than those treated by advanced life support paramedics. ${ }^{48}$ Across multiple studies, criticalcare transport teams with training in complex ventilator management are associated with improved $\mathrm{P}_{\mathrm{aO}_{2}}$ after transfer from outside facilities in patients with hypoxic respiratory failure. ${ }^{41,50,51}$ Wilcox et $\mathrm{al}^{41}$ describe a cohort in which high rates of neuromuscular blockade were observed; 58 subjects $(43.3 \%)$ received initial neuromuscular blockade from the critical care transport team. The transporting team changed ventilator settings during transport in $89 \%$ of the subjects, most commonly decreasing $\mathrm{V}_{\mathrm{T}}(35.9 \%$ of subjects), increasing PEEP (29.1\%), and increasing $\mathrm{F}_{\mathrm{IO}_{2}}$ $(30.1 \%) .^{41}$ These changes were associated with increases in $\mathrm{P}_{\mathrm{aO}_{2}}$ on arrival at the receiving facility. ${ }^{41}$ Increasing $\mathrm{F}_{\mathrm{IO}_{2}}$ and PEEP, and administration of neuromuscular blockade were most strongly associated with increased $\mathrm{P}_{\mathrm{aO}_{2}}$ after transport. In addition, ventilator changes were associated with reduced peak inspiratory pressure and trended toward reduced plateau pressures. Prehospital mechanical ventilation management not only influences oxygenation and critical events during transport but may also carry downstream effects as well. $\mathrm{V}_{\mathrm{T}}$ provided by prehospital aeromedical crews have been shown to influence initial hospital $\mathrm{V}_{\mathrm{T}}$, both in the emergency department and ICU. ${ }^{42}$

\section{Emergency Department Ventilation}

\section{Landscape of Mechanical Ventilation Provided in the Emergency Department}

Conservative estimates show that, in the United States, 250,000 patients are on mechanical ventilation in the emergency department annually. ${ }^{59}$ This rate is increasing, ${ }^{60,61}$ along with overcrowding and emergency department boarding of patients who are critically ill. ${ }^{62,63}$ A survey of emergency department directors revealed that $>90 \%$ of emergency departments report problems with crowding and that daily crowding occurred in 39\% of emergency departments, which resulted in delayed care and diagnosis in almost $40 \%$ of the patients. ${ }^{64}$ Crowding and prolonged boarding is associated with worsened mortality and prolonged mechanical ventilation duration. ${ }^{61,65-67}$ Increased duration of mechanical ventilation in the emergency department has been independently associated with increased mortality. ${ }^{67}$

Until recently, mechanical ventilation in the emergency department has received little attention in the literature outside of initial airway management. ${ }^{4}$ Survey studies showed that emergency physicians and trainees are often uncomfortable with ventilator management, 5,6 and multiple studies showed that potentially injurious ventilation is commonly delivered in the emergency department. $1,8,38$ Volume control continuous mandatory ventilation is the most common mode of mechanical ventilation used in the emergency department (65-90\% of patients). ${ }^{1,8,68}$ Analysis of the observational data from the emergency department showed that subjects received mean levels of PEEP of $\sim 5 \mathrm{~cm} \mathrm{H}_{2} \mathrm{O}$ and high $\mathrm{F}_{\mathrm{IO}_{2}}{ }^{1,8}$ A single-center study demonstrated median (interquartile range) emergency department $\mathrm{V}_{\mathrm{T}}$ to be $8.8(7.8-10.0) \mathrm{mL} / \mathrm{kg} \mathrm{PBW}$ and that lung-protective ventilation was delivered in only $27.1 \%$ of the subjects. ${ }^{1}$

Similar findings were observed in a multi-center study. Although a greater proportion of subjects in this cohort received lung-protective ventilation $(55.7 \%), 11.4 \%$ still received $\mathrm{V}_{\mathrm{T}}$ of $>10 \mathrm{~mL} / \mathrm{kg}$ PBW. ${ }^{8}$ In a cohort at a different network of centers described by Wilcox et al, ${ }^{68}$ approximately half of the subjects received ventilation with both $\mathrm{F}_{\mathrm{IO}_{2}}$ of 1.0 and PEEP of $\leq 5 \mathrm{~cm} \mathrm{H}_{2} \mathrm{O}$, and nearly $40 \%$ of the subjects received nonprotective ventilation. The median $\mathrm{F}_{\mathrm{IO}_{2}}$ in this cohort was 1.0, and the median PEEP was $5 \mathrm{~cm} \mathrm{H}_{2} \mathrm{O}$. Patients often receive prolonged exposure to both high $\mathrm{V}_{\mathrm{T}}$ values (median $\mathrm{V}_{\mathrm{T}}=230[0-320] \mathrm{min}$ ) and high $\mathrm{F}_{\mathrm{IO}_{2}}$ (median $\mathrm{V}_{\mathrm{T}}=251$ [148-373] min) while in the emergency department. ${ }^{7}$ Initial ventilator settings remain static in up to $78 \%$ of subjects in the emergency department for the duration of ventilation, which suggested that the historical practice of ventilator management in the emergency department did not involve active titration of settings. ${ }^{1,67,68}$

\section{Clinical Impact of Mechanical Ventilation in the Emergency Department}

As demonstrated by several cohort studies, the historical approach to mechanical ventilation in the emergency department involved the following: (1) relatively high $\mathrm{V}_{\mathrm{T}}$; (2) PEEP of $5 \mathrm{~cm} \mathrm{H}_{2} \mathrm{O}$; (3) $\mathrm{F}_{\mathrm{IO}_{2}}$ of 1.0; and (4) the delivery of mechanical ventilation in the supine, flat position. ${ }^{1,8,68}$ The LOV-ED (Lung-Protective Ventilation Initiated in the Emergency Department) trial was designed to target these practice patterns through a quality-improvement initiative with protocolized dosing of $\mathrm{V}_{\mathrm{T}}$, PEEP, $\mathrm{F}_{\mathrm{IO}_{2}}$, and head of bed elevation for subjects in the emergency department who are on mechanical ventilation. ${ }^{36,69}$ This protocol was largely driven by respiratory therapists who measured accurate heights in all subjects to effectively implement lungprotective $\mathrm{V}_{\mathrm{T}}$ based on PBW and titrated $\mathrm{F}_{\mathrm{IO}_{2}}$ and PEEP to maintain adequate oxygenation. ${ }^{36,69}$ The protocol that was used clinically is displayed in Figure 1. This protocol was effectively implemented, with a significant increase in lungprotective ventilation from $48.2 \%$ in the pre-intervention 


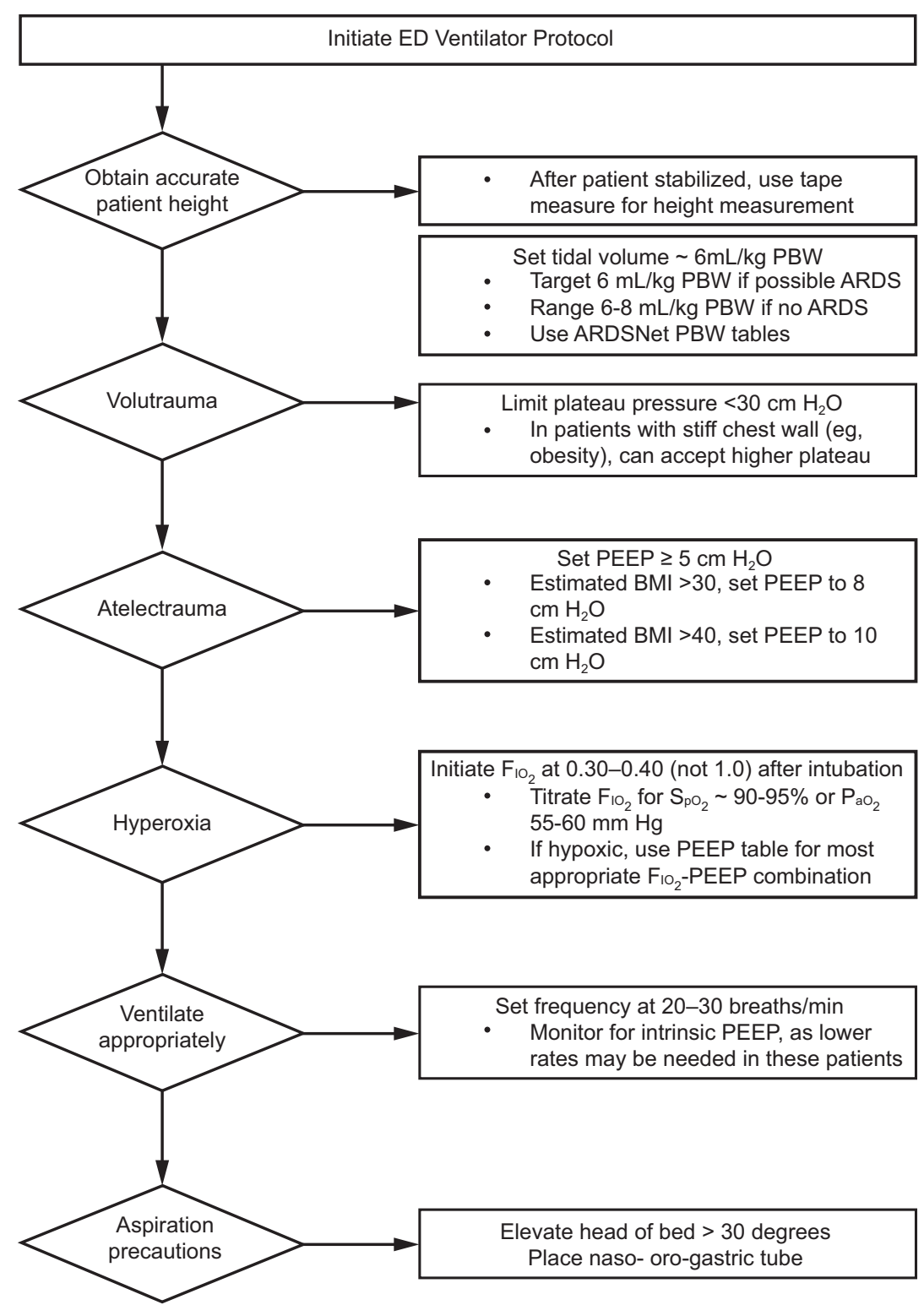

Fig. 1. Emergency department ventilator protocol. ED = emergency department; PBW = predicted body weight. From Reference 36, with permission.

cohort to $96.2 \%$ in the intervention cohort. Among subjects without ARDS, the post-intervention cohort received lower median dosing of $\mathrm{F}_{\mathrm{IO}_{2}}$ (median (IQR), 0.4 [0.4-0.6] versus $0.80[0.5-1.0])$ and $\mathrm{V}_{\mathrm{T}}(8.1[7.3-9.1] \mathrm{mL} / \mathrm{kg} \mathrm{PBW}$ versus $6.3[6.0-6.7] \mathrm{mL} / \mathrm{kg} \mathrm{PBW}) .36$

The LOV-ED protocol was associated with a reduction in mortality from $34.1 \%$ to $19.6 \%$ and a reduction in pulmonary complications (composite outcome of ARDS and ventilator-associated conditions) from $14.5 \%$ to $7.4 \%$. In addition, ventilator, ICU, and hospital-free days were greater among the subjects who received protocolized lung-protective ventilation while in the emergency department, with mean differences of $3.7,95 \%$ CI $2.3-$
$5.1 \mathrm{~d} ; 2.4,95 \%$ CI $1.0-3.7 \mathrm{~d}$; and $2.4,1.2-3.6 \mathrm{~d}$, respectively. ${ }^{36}$ Similar results were seen in the subjects with ARDS. Receipt of the emergency department-based lung-protective intervention was the only predictor of subjects with ARDS ever receiving lung protection in the ICU and was associated with a mortality reduction from $54.8 \%$ to $39.5 \%$ and with an increase in ventilatorfree days from 7.7 to 11.6. ${ }^{37}$ Results of both studies are detailed in Table 1.

Although analysis of these data indicated that emergency department lung-protective ventilation is associated with improved patient outcome, it is unclear whether the observed clinical benefit was secondary to mitigation of 
Table 1. Outcomes of Before-After Studies That Implemented Lung Protective Ventilation in the Emergency Department

\begin{tabular}{|c|c|c|c|c|c|}
\hline Study & Patients & Outcome & $\begin{array}{l}\text { Pre-Intervention } \\
\text { Group* }\end{array}$ & $\begin{array}{l}\text { Intervention } \\
\text { Group* }\end{array}$ & $\begin{array}{c}\text { Adjusted Odds } \\
\text { Ratio or } \\
\text { Between-Group } \\
\text { Difference, 95\% CI }\end{array}$ \\
\hline \multirow[t]{9}{*}{ Fuller et al, ${ }^{36} 2017 \dagger$} & \multirow{9}{*}{$\begin{array}{l}\text { Subjects without ARDS } \\
\text { and who were on } \\
\text { mechanical ventilation }\end{array}$} & Subjects & 490 & 490 & \\
\hline & & Primary composite outcomes & $71(14.5)$ & $36(7.4)$ & $0.47,0.31-0.71$ \\
\hline & & ARDS & $53(10.8)$ & $20(4.1)$ & $0.35,0.21-0.60$ \\
\hline & & VAC & $37(7.6)$ & $23(4.7)$ & $0.60,0.35-1.03$ \\
\hline & & Secondary outcomes & & & \\
\hline & & Ventilator-free days & $14.7 \pm 11.7$ & $18.4 \pm 10.4$ & $3.7,2.3-5.1$ \\
\hline & & Hospital-free days & $9.4 \pm 9.5$ & $11.7 \pm 9.2$ & $2.4,1.2-3.6$ \\
\hline & & ICU-free days & $13.6 \pm 11.1$ & $16.0 \pm 9.9$ & $2.4,1.0-3.7$ \\
\hline & & Mortality & $167(34.1)$ & $96(19.6)$ & $0.47,0.35-0.63$ \\
\hline \multirow[t]{6}{*}{ Fuller et al, ${ }^{37} 2017$} & \multirow{6}{*}{$\begin{array}{l}\text { Subjects with ARDS } \\
\text { (onset in emergency } \\
\text { department or ICU) } \\
\text { and on mechanical } \\
\text { ventilation }\end{array}$} & Subjects & 186 & 43 & \\
\hline & & Mortality§ & $102(54.8)$ & $17(39.5)$ & $0.36,0.16-0.82$ \\
\hline & & Secondary outcomes & & & \\
\hline & & Ventilator-free days & $7.7 \pm 9.9$ & $11.6 \pm 10.8$ & $4.0,0.6-7.3$ \\
\hline & & ICU-free days & $7.2 \pm 9.4$ & $9.1 \pm 9.2$ & $1.9,-1.2$ to 5.0 \\
\hline & & Hospital-free days & $4.0 \pm 6.3$ & $5.7 \pm 7.7$ & $1.6,-0.9$ to 4.2 \\
\hline \multicolumn{6}{|c|}{$\begin{array}{l}\text { * Data are mean } \pm \mathrm{SD} \text { or } n(\%) \text {. } \\
\uparrow \text { Outcomes are reported from a propensity score-matched analysis. } 36 \\
\text { † The primary outcome was a composite of the event rate of VAC and ARDS, which represent patient-centered pulmonary complications; primary outcome and mortality were evaluated by using a } \\
\text { logistic regression model. } \\
\S \text { Mortality was evaluated by using a logistic regression model. } \\
\text { VAC = ventilator-associated conditions }\end{array}$} \\
\hline
\end{tabular}

ventilator-induced lung injury, reduced hyperoxia, or some therapeutic combination. Analysis of the clinical data showed that hyperoxia is associated with worse outcomes across a wide range of patients, including acute coronary syndrome and after cardiac arrest. However, these data had largely been limited to hyperoxia observed in the ICU. ${ }^{70,71}$ An a priori planned substudy ${ }^{7}$ of the LOV-ED trial demonstrated increased mortality in the subjects with hyperoxia $\left(\mathrm{P}_{\mathrm{aO}_{2}}>120 \mathrm{~mm} \mathrm{Hg}\right)$ in the emergency department $(29.7 \%$ vs $19.4 \%)$. There was a dose-dependent relationship between increasing ranges of hyperoxia and observed mortality as well (Fig. 2). Although clinicians recognize the negative impacts of hyperoxia, this typically is not reflected in their oxygen administration patterns. ${ }^{72,73}$ As such, hyperoxia is common in patients on mechanical ventilation in the ICU and the emergency department, and a possible target for improved outcomes. ${ }^{7,72}$

\section{Summary and Recommendations}

As demonstrated in this review, mechanical ventilation in the prehospital and emergency department settings (1) influences how the ventilator is managed after ICU admission, and (2) impacts patient outcome. Providers in these arenas, therefore, should strive to achieve the most-appropriate and safe ventilator settings on an individual patient level. Interfacility transfer of patients who are hypoxemic

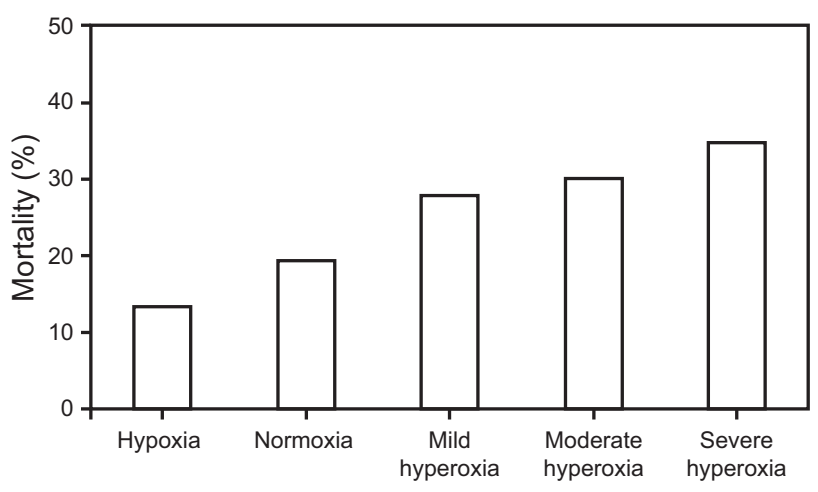

Fig. 2. Mortality across oxygenation subgroups. Hypoxia, $\mathrm{P}_{\mathrm{aO}_{2}}$ $<60 \mathrm{~mm} \mathrm{Hg}$; normoxia, $\mathrm{P}_{\mathrm{aO}}, 60-120 \mathrm{~mm} \mathrm{Hg}$; mild hyperoxia, $\mathrm{P}_{\mathrm{aO}}$ 121-200 mm Hg; moderate hyperoxia, $\mathrm{P}_{\mathrm{aO}}{ }_{2} 201-300$ mm Hg; severe hyperoxia, $\mathrm{P}_{\mathrm{aO}_{2}}>300 \mathrm{~mm} \mathrm{Hg}$. From Reference 7, with permission.

to higher levels of care (ie, a facility with extracorporeal membrane oxygenation capability) is feasible and safe, despite risks of deterioration and desaturation to the patient. In the prehospital environment, strong consideration should be given to avoidance of adult bag-valve-masks in all patients to avoid the dangers of hyperventilation and hypocapnia as well as the delivery of unnecessarily large $V_{T}$ values. When possible, a transport ventilator should be used or the adult bag-valve-mask should be replaced with a pediatricsized bag-valve-mask to minimize delivery of $\mathrm{V}_{\mathrm{T}}$ that exceed 
lung-protective ventilation targets. ${ }^{44}$ Hypocapnia can be avoided by titration of ventilation based on end-tidal capnometry to reduce the risk of hyperventilation. Despite a paucity of patient-centered outcome data, we agree with previous recommendations to use a disposable, adjustable PEEP valve when providing bag-mask ventilation, titrating PEEP dosing to patient oxygen saturation.

For the vast majority of patients who receive mechanical ventilation in the prehospital or emergency department setting, we recommend that lung-protective $\mathrm{V}_{\mathrm{T}}$ $(6-8 \mathrm{~mL} / \mathrm{kg} \mathrm{PBW})$ be the default approach. It should also be noted that data from large academic medical centers demonstrated that $\sim 8 \%$ of patients on mechanical ventilation in the emergency department have acute lung injury. ${ }^{3,74}$ Therefore, dosing $\mathrm{V}_{\mathrm{T}}$ closer to the 6 $\mathrm{mL} / \mathrm{kg}$ PBW end of the range as an initial approach may serve to improve the outcome in this cohort. To avoid hyperoxia, as opposed to the traditional approach of administering $\mathrm{F}_{\mathrm{IO}_{2}}$ of 1.0 at the initiation of mechanical ventilation, we recommend starting at $0.3-0.4$ and only titrating up when needed, and in combination with PEEP. To streamline care, we recommend bundled ventilator protocols to help achieve implementation of best practices, and recommend a team approach, with heavy involvement from respiratory therapy. The lung-protective ventilation protocol used successfully in the LOV-ED study is displayed in Figure 1.

Although we recommend the effective implementation of protocols to reduce the unnecessary practice variability that surrounds postintubation mechanical ventilation, this does not replace the clinical decision making at the bedside with respect to dynamic ventilator adjustments. The implementation of a lung-protective ventilation protocol has proven safe and feasible, and is associated with improved outcome in patients on mechanical ventilation. However, it is not appropriate for all patients with acute respiratory failure (ie, life-threatening acidemia, expiratory flow limitation, and intrinsic PEEP [asthma, COPD]). ${ }^{75,76} \mathrm{Al}-$ though high minute ventilation is often used to reduce $\mathrm{P}_{\mathrm{aCO}_{2}}$ transiently in the setting of acute brain herniation, maintenance of normocapnia is recommended in patients with brain injury. ${ }^{77}$

Protocols in patients with and without ARDS allow for set frequency adjustments up to 30-35 breaths $/ \mathrm{min}^{36,78}$; In most patients, this does not result in clinically important increases in intrinsic PEEP and can typically maintain normocapnia. ${ }^{79}$ This method has been shown to be safe in patients with brain injury and gives providers the flexibility to titrate ventilation to achieve appropriate $\mathrm{P}_{\mathrm{aCO}_{2}}$ levels while providing lung-protective $\mathrm{V}_{\mathrm{T}} \cdot{ }^{80}$ Further, lung-protective ventilation in the setting of brain injury is well tolerated physiologically and is associated with improved outcomes. ${ }^{81}$ Therefore, the presence of brain injury should NOT preclude clinicians from attempting to use lung-pro- tective ventilation. Finally, among the most important findings of this review was that there is a relative paucity of literature in the realm of prehospital and emergency ventilation. Given the importance of this topic, we believe that this is an area that is ripe for further study.

\section{REFERENCES}

1. Fuller BM, Mohr NM, Dettmer M, Kennedy S, Cullison K, Bavolek $\mathrm{R}$, et al. Mechanical ventilation and acute lung injury in emergency department patients with severe sepsis and septic shock: an observational study. Acad Emerg Med 2013;20(7):659-669.

2. Gajic O, Frutos-Vivar F, Esteban A, Hubmayr RD, Anzueto A. Ventilator settings as a risk factor for acute respiratory distress syndrome in mechanically ventilated patients. Intensive Care Med 2005; 31(7):922-926.

3. Hou PC, Elie-Turenne MC, Mitani A, Barry JM, Kao EY, Cohen JE, et al.; US Critical Illness and Injury Trials Group: Lung Injury Prevention Study Investigators (USCIITG-LIPS 1). Towards prevention of acute lung injury: frequency and outcomes of emergency department patients at-risk: a multicenter cohort study. Int J Emerg Med 2012;5(1):22.

4. Fuller BM, Mohr NM, Drewry AM, Carpenter CR. Lower tidal volume at initiation of mechanical ventilation may reduce progression to acute respiratory distress syndrome: a systematic review. Crit Care 2013;17(1):R11.

5. Wilcox SR, Seigel TA, Strout TD, Schneider JI, Mitchell PM, Marcolini EG, et al. Emergency medicine residents' knowledge of mechanical ventilation. J Emerg Med 2015;48(4):481-491.

6. Wilcox SR, Strout TD, Schneider JI, Mitchell PM, Smith J, LutfyClayton L, et al. Academic emergency medicine physicians' knowledge of mechanical ventilation. West J Emerg Med 2016;17(3):271279.

7. Page D, Ablordeppey E, Wessman BT, Mohr NM, Trzeciak S, Kollef $\mathrm{MH}$, et al. Emergency department hyperoxia is associated with increased mortality in mechanically ventilated patients: a cohort study. Crit Care 2018;22(1):9.

8. Fuller BM, Mohr NM, Miller CN, Deitchman AR, Levine BJ, Castagno N, et al. Mechanical ventilation and ARDS in the ED: a multicenter, observational, prospective, cross-sectional study. Chest 2015; 148(2):365-374.

9. Stephens RJ, Ablordeppey E, Drewry AM, Palmer C, Wessman BT, Mohr NM, et al. Analgosedation practices and the impact of sedation depth on clinical outcomes among patients requiring mechanical ventilation in the emergency department: a cohort study. Chest 2017; 152(5):963-971.

10. Bhat R, Goyal M, Graf S, Bhooshan A, Teferra E, Dubin J, Frohna B. Impact of post-intubation interventions on mortality in patients boarding in the emergency department. West J Emerg Med 2014; 15(6):708-711.

11. Slutsky AS, Ranieri VM. Ventilator-induced lung injury. N Engl J Med 2013;369(22):2126-2136.

12. Al Ghouleh I, Khoo NK, Knaus UG, Griendling KK, Touyz RM, Thannickal VJ, et al. Oxidases and peroxidases in cardiovascular and lung disease: new concepts in reactive oxygen species signaling. Free Radic Biol Med 2011;51(7):1271-1288.

13. Becker LB. New concepts in reactive oxygen species and cardiovascular reperfusion physiology. Cardiovasc Res 2004;61(3):461-470.

14. Ranieri VM, Suter PM, Tortorella C, De Tullio R, Dayer JM, Brienza A, et al. Effect of mechanical ventilation on inflammatory mediators in patients with acute respiratory distress syndrome: a randomized controlled trial. JAMA 1999;282(1):54-61. 


\section{Prehospital and Emergency Department Mechanical Ventilation}

15. Protti A, Cressoni M, Santini A, Langer T, Mietto C, Febres D, et al. Lung stress and strain during mechanical ventilation: any safe threshold? Am J Respir Crit Care Med 2011;183(10):1354-1362.

16. Protti A, Andreis DT, Milesi M, Iapichino GE, Monti M, Comini B, et al. Lung anatomy, energy load, and ventilator-induced lung injury. Intensive Care Med Exp 2015;3(1):34.

17. Cressoni M, Cadringher P, Chiurazzi C, Amini M, Gallazzi E, Marino A, et al. Lung inhomogeneity in patients with acute respiratory distress syndrome. Am J Respir Crit Care Med 2014;189(2):149158.

18. Gattinoni L, Marini JJ, Pesenti A, Quintel M, Mancebo J, Brochard L. The "baby lung" became an adult. Intensive Care Med 2016; 42(5):663-673.

19. Gattinoni L, Pesenti A. The concept of "baby lung". Intensive Care Med 2005;31(6):776-784.

20. Helmerhorst HJF, Schouten LRA, Wagenaar GTM, Juffermans NP, Roelofs JJTH, Schultz MJ, et al. Hyperoxia provokes a time- and dose-dependent inflammatory response in mechanically ventilated mice, irrespective of tidal volumes. Intensive Care Med Exp 2017; 5(1):27.

21. Cavassani SS, Junqueira VB, Moraes JB, Luzo KK, Silva CM, Bar$\operatorname{ros} \mathrm{M}$, et al. Short courses of mechanical ventilation with high-O2 levels in elderly rat lungs. Acta Cir Bras 2011;26(2):107-113.

22. Li LF, Liao SK, Ko YS, Lee CH, Quinn DA. Hyperoxia increases ventilator-induced lung injury via mitogen-activated protein kinases: a prospective, controlled animal experiment. Crit Care 2007;11(1): R25.

23. Pontoppidan H, Geffin B, Lowenstein E. Acute respiratory failure in the adult. 1. N Engl J Med 1972;287(14):690-698.

24. Dreyfuss D, Soler P, Basset G, Saumon G. High inflation pressure pulmonary edema. Respective effects of high airway pressure, high tidal volume, and positive end-expiratory pressure. Am Rev Respir Dis 1988;137(5):1159-1164.

25. Webb HH, Tierney DF. Experimental pulmonary edema due to intermittent positive pressure ventilation with high inflation pressures. Protection by positive end-expiratory pressure. Am Rev Respir Dis 1974;110(5):556-565

26. Muscedere JG, Mullen JB, Gan K, Slutsky AS. Tidal ventilation at low airway pressures can augment lung injury. Am J Respir Crit Care Med 1994;149(5):1327-1334.

27. Determann RM, Royakkers A, Wolthuis EK, Vlaar AP, Choi G, Paulus F, et al. Ventilation with lower tidal volumes as compared with conventional tidal volumes for patients without acute lung injury: a preventive randomized controlled trial. Crit Care 2010;14(1): R1.

28. Serpa Neto A, Cardoso SO, Manetta JA, Pereira VG, Espósito DC, Pasqualucci Mde O, et al. Association between use of lung-protective ventilation with lower tidal volumes and clinical outcomes among patients without acute respiratory distress syndrome: a meta-analysis. JAMA 2012;308(16):1651-1659.

29. Futier E, Constantin JM, Paugam-Burtz C, Pascal J, Eurin M, Neuschwander A, et al.; IMPROVE Study Group. A trial of intraoperative low-tidal-volume ventilation in abdominal surgery. $\mathrm{N}$ Engl J Med 2013;369(5):428-437.

30. Licker M, Diaper J, Villiger Y, Spiliopoulos A, Licker V, Robert J, Tschopp JM. Impact of intraoperative lung-protective interventions in patients undergoing lung cancer surgery. Crit Care 2009;13(2): R41.

31. Michelet P, D’Journo XB, Roch A, Doddoli C, Marin V, Papazian L, et al. Protective ventilation influences systemic inflammation after esophagectomy: a randomized controlled study. Anesthesiology 2006; 105(5):911-919.

32. Fuller BM, Page D, Stephens RJ, Roberts BW, Drewry AM, Ablordeppey E, et al. Pulmonary mechanics and mortality in me- chanically ventilated patients without acute respiratory distress syndrome: a cohort study. Shock 2018;49(3):311-316.

33. Gajic O, Dara SI, Mendez JL, Adesanya AO, Festic E, Caples SM, et al. Ventilator-associated lung injury in patients without acute lung injury at the onset of mechanical ventilation. Crit Care Med 2004; 32(9):1817-1824.

34. Yilmaz M, Keegan MT, Iscimen R, Afessa B, Buck CF, Hubmayr $\mathrm{RD}$, et al. Toward the prevention of acute lung injury: protocolguided limitation of large tidal volume ventilation and inappropriate transfusion. Crit Care Med 2007;35(7):1660-1666, quiz 1667.

35. Needham DM, Yang T, Dinglas VD, Mendez-Tellez PA, Shanholtz C, Sevransky JE, et al. Timing of low tidal volume ventilation and intensive care unit mortality in acute respiratory distress syndrome. A prospective cohort study. Am J Respir Crit Care Med 2015;191(2): 177-185.

36. Fuller BM, Ferguson IT, Mohr NM, Drewry AM, Palmer C, Wessman BT, et al. Lung-Protective Ventilation Initiated in the Emergency Department (LOV-ED): a quasi-experimental, before-after trial. Ann Emerg Med 2017;70(3):406-418.e4.

37. Fuller BM, Ferguson IT, Mohr NM, Drewry AM, Palmer C, Wessman BT, et al. A quasi-experimental, before-after trial examining the impact of an emergency department mechanical ventilator protocol on clinical outcomes and lung-protective ventilation in acute respiratory distress syndrome. Crit Care Med 2017;45(4):645-652.

38. Sjoding MW, Gong MN, Haas CF, Iwashyna TJ. Evaluating delivery of low tidal volume ventilation in six ICUs using electronic health record data. Crit Care Med 2019;47(1):56-61.

39. Fuller BM, Mohr N, Skrupky L, Mueller K, McCammon C. Emergency department vancomycin use: Dosing practices and associated outcomes. J Emerg Med 2013;44(5):910-918.

40. Wang HE, Mann NC, Mears G, Jacobson K, Yealy DM. Out-ofhospital airway management in the United States. Resuscitation 2011; 82(4):378-385

41. Wilcox SR, Saia MS, Waden H, Frakes M, Wedel SK, Richards JB. Mechanical ventilation in critical care transport. Air Med J 2016; 35(3):161-165.

42. Stoltze AJ, Wong TS, Harland KK, Ahmed A, Fuller BM, Mohr NM. Prehospital tidal volume influences hospital tidal volume: a cohort study. J Crit Care 2015;30(3):495-501.

43. Weiss SJ, Ernst AA, Jones R, Ong M, Filbrun T, Augustin C, et al. Automatic transport ventilator versus bag valve in the EMS setting: a prospective, randomized trial. South Med J 2005;98(10):970-976.

44. Siegler J, Kroll M, Wojcik S, Moy HP. Can EMS providers provide appropriate tidal volumes in a simulated adult-sized patient with a pediatric-sized bag-valve-mask? Prehosp Emerg Care 2017;21(1): 74-78.

45. Turki M, Young MP, Wagers SS, Bates JH. Peak pressures during manual ventilation. Respir Care 2005;50(3):340-344.

46. Weingart SD, Levitan RM. Preoxygenation and prevention of desaturation during emergency airway management. Ann Emerg Med 2012;59(3):165-175.e1

47. Kroll M, Das J, Siegler J. Can altering grip technique and bag size optimize volume delivered with bag-valve-mask by emergency medical service providers? Prehosp Emerg Care 2019;23(2):210-214.

48. Singh JM, MacDonald RD, Ahghari M. Critical events during landbased interfacility transport. Ann Emerg Med 2014;64(1):9-15.e2.

49. Singh JM, MacDonald RD, Bronskill SE, Schull MJ. Incidence and predictors of critical events during urgent air-medical transport. CMAJ 2009;181(9):579-584.

50. Wilcox SR, Saia MS, Waden H, Genthon A, Gates JD, Cocchi MN, et al. Improved oxygenation after transport in patients with hypoxemic respiratory failure. Air Med J 2015;34(6):369-376.

51. Uusaro A, Parviainen I, Takala J, Ruokonen E. Safe long-distance interhospital ground transfer of critically ill patients with acute se- 


\section{Prehospital and Emergency Department Mechanical Ventilation}

vere unstable respiratory and circulatory failure. Intensive Care Med 2002;28(8):1122-1125.

52. Davis DP, Heister R, Poste JC, Hoyt DB, Ochs M, Dunford JV. Ventilation patterns in patients with severe traumatic brain injury following paramedic rapid sequence intubation. Neurocrit Care 2005; 2(2):165-171.

53. Helm M, Hauke J, Lampl L. A prospective study of the quality of pre-hospital emergency ventilation in patients with severe head injury. Br J Anaesth 2002;88(3):345-349.

54. Davis DP, Dunford JV, Poste JC, Ochs M, Holbrook T, Fortlage D, et al. The impact of hypoxia and hyperventilation on outcome after paramedic rapid sequence intubation of severely head-injured patients. J Trauma 2004;57(1):1-8, discussion 8-10.

55. Dumont TM, Visioni AJ, Rughani AI, Tranmer BI, Crookes B. Inappropriate prehospital ventilation in severe traumatic brain injury increases in-hospital mortality. J Neurotrauma 2010;27(7):1233-1241.

56. Warner KJ, Cuschieri J, Copass MK, Jurkovich GJ, Bulger EM. The impact of prehospital ventilation on outcome after severe traumatic brain injury. J Trauma 2007;62(6):1330-1336, discussion 1336-1338.

57. Roberts BW, Karagiannis P, Coletta M, Kilgannon JH, Chansky ME, Trzeciak S. Effects of $\mathrm{P}_{\mathrm{aCO}}$ derangements on clinical outcomes after cerebral injury: a systematic review. Resuscitation 2015;91:32-41.

58. Davis DP, Dunford JV, Ochs M, Park K, Hoyt DB. The use of quantitative end-tidal capnometry to avoid inadvertent severe hyperventilation in patients with head injury after paramedic rapid sequence intubation. J Trauma 2004;56(4):808-814.

59. Easter BD, Fischer C, Fisher J. The use of mechanical ventilation in the ED. Am J Emerg Med 2012;30(7):1183-1188.

60. Needham DM, Bronskill SE, Calinawan JR, Sibbald WJ, Pronovost PJ, Laupacis A. Projected incidence of mechanical ventilation in Ontario to 2026: preparing for the aging baby boomers. Crit Care Med 2005;33(3):574-579.

61. Singer AJ, Thode HC Jr, Viccellio P, Pines JM. The association between length of emergency department boarding and mortality. Acad Emerg Med 2011;18(12):1324-1329.

62. Mullins PM, Goyal M, Pines JM. National growth in intensive care unit admissions from emergency departments in the United States from 2002 to 2009. Acad Emerg Med 2013;20(5):479-486.

63. Cowan RM, Trzeciak S. Clinical review: emergency department overcrowding and the potential impact on the critically ill. Crit Care 2005;9(3):291-295.

64. Derlet R, Richards J, Kravitz R. Frequent overcrowding in U.S. emergency departments. Acad Emerg Med 2001;8(2):151-155.

65. Al-Qahtani S, Alsultan A, Haddad S, Alsaawi A, Alshehri M, Alsolamy $\mathrm{S}$, et al. The association of duration of boarding in the emergency room and the outcome of patients admitted to the intensive care unit. BMC Emerg Med 2017;17(1):34.

66. Cardoso LT, Grion CM, Matsuo T, Anami EH, Kauss IA, Seko L, Bonametti AM. Impact of delayed admission to intensive care units on mortality of critically ill patients: a cohort study. Crit Care 2011; 15(1):R28.

67. Angotti LB, Richards JB, Fisher DF, Sankoff JD, Seigel TA, Al Ashry HS, Wilcox SR. Duration of mechanical ventilation in the emergency department. West J Emerg Med 2017;18(5):972-979.
68. Wilcox SR, Richards JB, Fisher DF, Sankoff J, Seigel TA. Initial mechanical ventilator settings and lung protective ventilation in the ED. Am J Emerg Med 2016;34(8):1446-1451.

69. Fuller BM, Ferguson I, Mohr NM, Stephens RJ, Briscoe CC, Kolomiets AA, et al. Lung-protective ventilation initiated in the emergency department (LOV-ED): a study protocol for a quasi-experimental, before-after trial aimed at reducing pulmonary complications. BMJ Open 2016;6(4):e010991.

70. Kilgannon JH, Jones AE, Shapiro NI, Angelos MG, Milcarek B, Hunter K, et al.; Emergency Medicine Shock Research Network (EMShockNet) Investigators Association between arterial hyperoxia following resuscitation from cardiac arrest and in-hospital mortality. JAMA 2010;303(21):2165-2171.

71. de Jonge E, Peelen L, Keijzers PJ, Joore H, de Lange D, van der Voort PH, et al. Association between administered oxygen, arterial partial oxygen pressure and mortality in mechanically ventilated intensive care unit patients. Crit Care 2008;12(6):R156.

72. Helmerhorst HJ, Schultz MJ, van der Voort PH, Bosman RJ, Juffermans NP, de Jonge E, et al. Self-reported attitudes versus actual practice of oxygen therapy by ICU physicians and nurses. Ann Intensive Care 2014;4:23.

73. de Graaff AE, Dongelmans DA, Binnekade JM, de Jonge E. Clinicians' response to hyperoxia in ventilated patients in a Dutch ICU depends on the level of $\mathrm{F}_{\mathrm{IO}_{2}}$. Intensive Care Med 2011;37(1):46-51.

74. Goyal M, Houseman D, Johnson NJ, Christie J, Mikkelsen ME, Gaieski DF. Prevalence of acute lung injury among medical patients in the emergency department. Acad Emerg Med 2012;19(9):E10111018.

75. Stather DR, Stewart TE. Clinical review: mechanical ventilation in severe asthma. Crit Care 2005;9(6):581-587.

76. Leatherman JW, McArthur C, Shapiro RS. Effect of prolongation of expiratory time on dynamic hyperinflation in mechanically ventilated patients with severe asthma. Crit Care Med 2004;32(7):15421545.

77. Asehnoune K, Roquilly A, Cinotti R. Respiratory management in patients with severe brain injury. Crit Care 2018;22(1):76.

78. Acute Respiratory Distress Syndrome Network, Brower RG, Matthay MA, Morris A, Schoenfeld D, Thompson BT, Wheeler A. Ventilation with lower tidal volumes as compared with traditional tidal volumes for acute lung injury and the acute respiratory distress syndrome. N Engl J Med 2000;342(18):1301-1308.

79. Hough CL, Kallet RH, Ranieri VM, Rubenfeld GD, Luce JM, Hudson LD. Intrinsic positive end-expiratory pressure in Acute Respiratory Distress Syndrome (ARDS) network subjects. Crit Care Med 2005;33(3):527-532.

80. Asehnoune K, Mrozek S, Perrigault PF, Seguin P, Dahyot-Fizelier C, Lasocki S, et al.; BI-VILI study group. A multi-faceted strategy to reduce ventilation-associated mortality in brain-injured patients. The BI-VILI project: a nationwide quality improvement project. Intensive Care Med 2017;43(7):957-970.

81. Roquilly A, Cinotti R, Jaber S, Vourc'h M, Pengam F, Mahe PJ, et al. Implementation of an evidence-based extubation readiness bundle in 499 brain-injured patients. a before-after evaluation of a quality improvement project. Am J Respir Crit Care Med 2013;188(8): 958-966. 